\title{
Does control influence the growth of diabetic children?
}

\author{
S. K. M. JIVANI and P. H. W. RAYNER \\ From the Institute of Child Health, University of Birmingham, and The Children's Hospital, \\ Ladywood Middleway, Birmingham
}

\begin{abstract}
Jivani, S. K. M., and Rayner, P. H. W. (1973). Archives of Disease in Childhood, 48, 109. Does control influence the growth of diabetic children? Growth of 60 girls and 56 boys is analysed both in terms of linear growth and growth velocity. The children were of normal height at the onset of diabetes and were shorter when analysed 3 years or more after the onset of diabetes. The growth retardation was not related to the degree of control of diabetes but was related to the duration of diabetes before the onset of puberty and was due to retarded and delayed peak growth at puberty.
\end{abstract}

In the preinsulin era the growth of diabetic children who survived any length of time was severely retarded (Joslin, Root, and White, 1925). After the introduction of insulin the situation improved dramatically, but several authors have subsequently reported retarded growth in diabetic children (Wagner, White, and Bogan, 1942; Bergqvist, 1954; Danowski, 1957; Hamne, 1962; Sterky, 1963; Knowles et al., 1965; Sterky, 1967; Craig, 1970; Pond, 1970).

Some authors have considered that growth is related to the degree of control of diabetes (Boyd and Nelson, 1928; Boyd and Kantrow, 1938; Jackson and Kelly, 1946; Bergqvist, 1954; Pond, 1970). However, others found no relation (Wagner et al., 1942; Danowski, 1957; Sterky, 1963; Sterky, 1967; Craig, 1970). Despite these conflicting reports, normal growth has traditionally been accepted as a useful long-term index of satisfactory control. We have, therefore, undertaken this study to assess the value of this parameter.

\section{Materials and methods}

Children studied. The study was based on 116 children ( 60 girls and 56 boys) currently and previously attending the Birmingham Children's Hospital. Children with any other condition which might have affected growth were excluded.

Management. Management has remained essentially unchanged over the past 15 years. A regulated carbohydrate diet is given providing $40 \%$ of the total calorie intake. Calorie requirements in individual children vary but as a guide a 1 -year-old child is given $100 \mathrm{~g}$ carbohydrate and this is increased by $10 \mathrm{~g}$ a year until puberty. Most children were given a once-daily injection of a mixture of amorphous and crystalline insulin zinc suspension in proportions adjusted at the

Received 20 June 1972. clinic and by the parents at home. Some were given a mixture of soluble and isophane insulins twice daily at adolescence.

Assessment of control. The criteria of control are shown in Table I. Records of diet, insulin requirements, physical examination, episodes of ketosis and hypoglycaemia, and blood sugar levels were available for each child. Each child at each clinic visit was graded on the basis of urine testing at home and clinic records of glycosuria, ketosis, blood sugar levels, and incidence of hypoglycaemia. For the purpose of this study two groups have been defined: those having on aggregate predominantly good control or predominantly poor control.

Growth assessment. The ages at onset of diabetic children are shown in Fig. 1a and $1 \mathrm{~b}$ for girls and boys. The range was from 1 year to 13 years for girls and from 9 months to 13 years for boys. Only children followed up for more than 3 years are included in the series (range 3 years to 13 years with an average followup for girls of 7.17 years and for boys $6 \cdot 64$ years). Growth has been compared with the standards for British children of Tanner, Whitehouse, and Takaishi (1966) and has been analysed both in terms of linear growth and growth velocity. Centile channels I to VIII have been added to facilitate analysis of results. The height at onset of an additional group diagnosed in the past 5 years and currently attending the clinic has been analysed separately to detect any secular change in height.

Methods of analysis. A convenient and a reasonably accurate way of combining the heights for age of a group of subjects is to regard an individual's height in a particular channel (channels I-VIII on Tanner and Whitehouse growth charts) as being at the midpoint on that channel. Thus, if at the onset of diabetes there are 10 children in channel $\mathrm{V}$, i.e. between the 50th and 75th centile, their heights are regarded as being at a centile value of $62 \cdot 5$. In this way a mean centile value (MPV) of a 
TABLE I

Criteria used for assessment of diabetic control

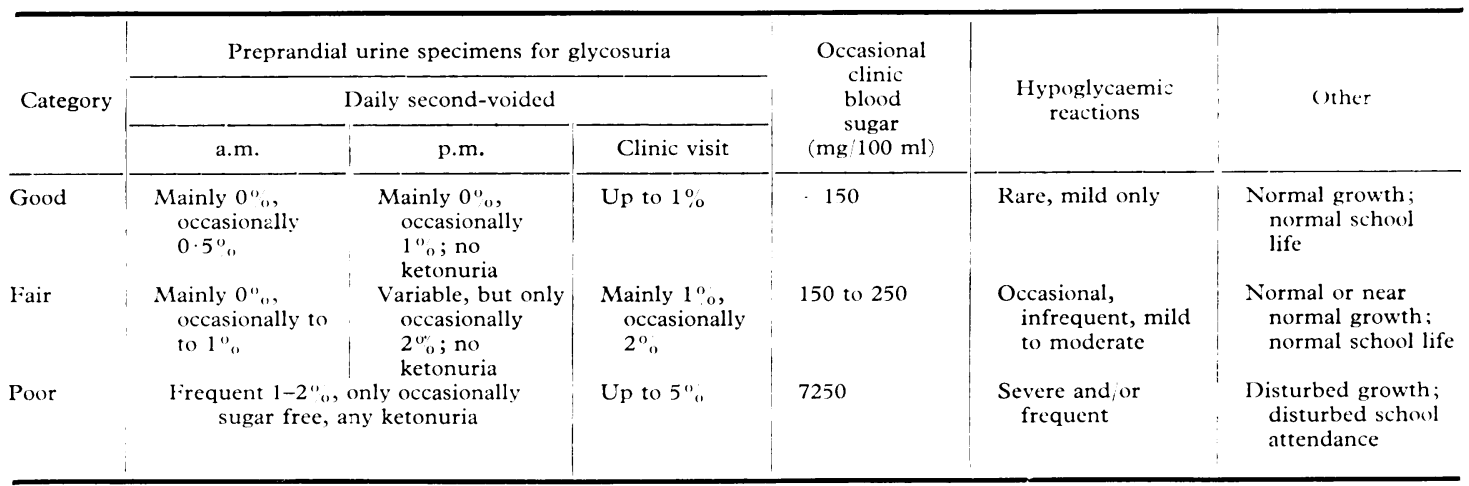

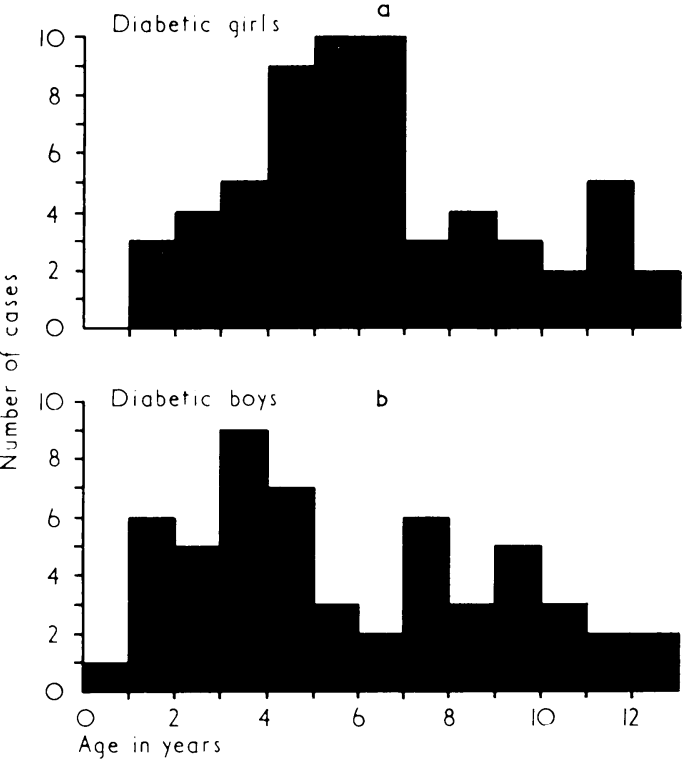

Fig. 1.-(a) Age of onset of diabetes, 60 cases analysed (girls). (b) Age of onset of diabetes, 54 cases analysed (boys).

group of children can be calculated. The expected MPV of a group of normal children can be taken as 50 . Height velocities per year were calculated for each child and from this the mean was determined. The groups were divided into good control and poor control according to the criteria given above and their growth patterns separately analysed. Growth in childhood may be divided into three phases, (i) rapid growth during infancy, (ii) a midchildhood plateau, and (iii) the pubertal growth spurt. In order to assess whether diabetes affected growth differently in these separate phases, three further subgroups were also analysed. (1) Onset of diabetes before 6 years of age and analyses at 9 years for girls and 10 years for boys. (2) Onset at or around 9 years for girls and 10 years for boys, and analysis after puberty had been completed. (3) Onset before 6 years, analysis after puberty.

\section{Results}

Height at onset and analysis. Fig. $2 a$ and $2 b$ show the heights at onset and analysis for girls and boys, respectively. At the onset of diabetes height lies close to the 50th centile, but at analysis there are more below than above it. Fig. 3a and $3 \mathrm{~b}$ compare the expected number of children in each channel in a normal population and the actual number of children present in each channel at onset of diabetes and at analysis. A shift to the left at analysis is apparent indicating that their height is retarded.

Analysis for girls. Tables II and III show the mean centile value at onset and analysis for girls. It can be seen that height at onset of diabetes is not statistically different from the 50th centile. When analysed at varying periods of follow-up (range 3 to 13 years, with a mean of $7 \cdot 1$ years) they were, however, significantly shorter than the 50th centile $(0.005>\mathbf{P}>0.001)$ and their height centile had fallen significantly on a 'within patient' basis ( $P<0.001)$. When analysed by grade of control, both the well and poorly controlled girls were shorter than the 50th centile at analysis $(0.05>P>0.025$ for both groups) and their height centile had fallen significantly on a 'within patient' basis $(0.005>\mathbf{P}>0.001$ and $0.025>P>0.02$ for well controlled and poorly controlled, respectively). The degree of the control of diabetes does not appear to have affected the pattern of growth. On analysing the subgroups there is no statistically significant retardation of 

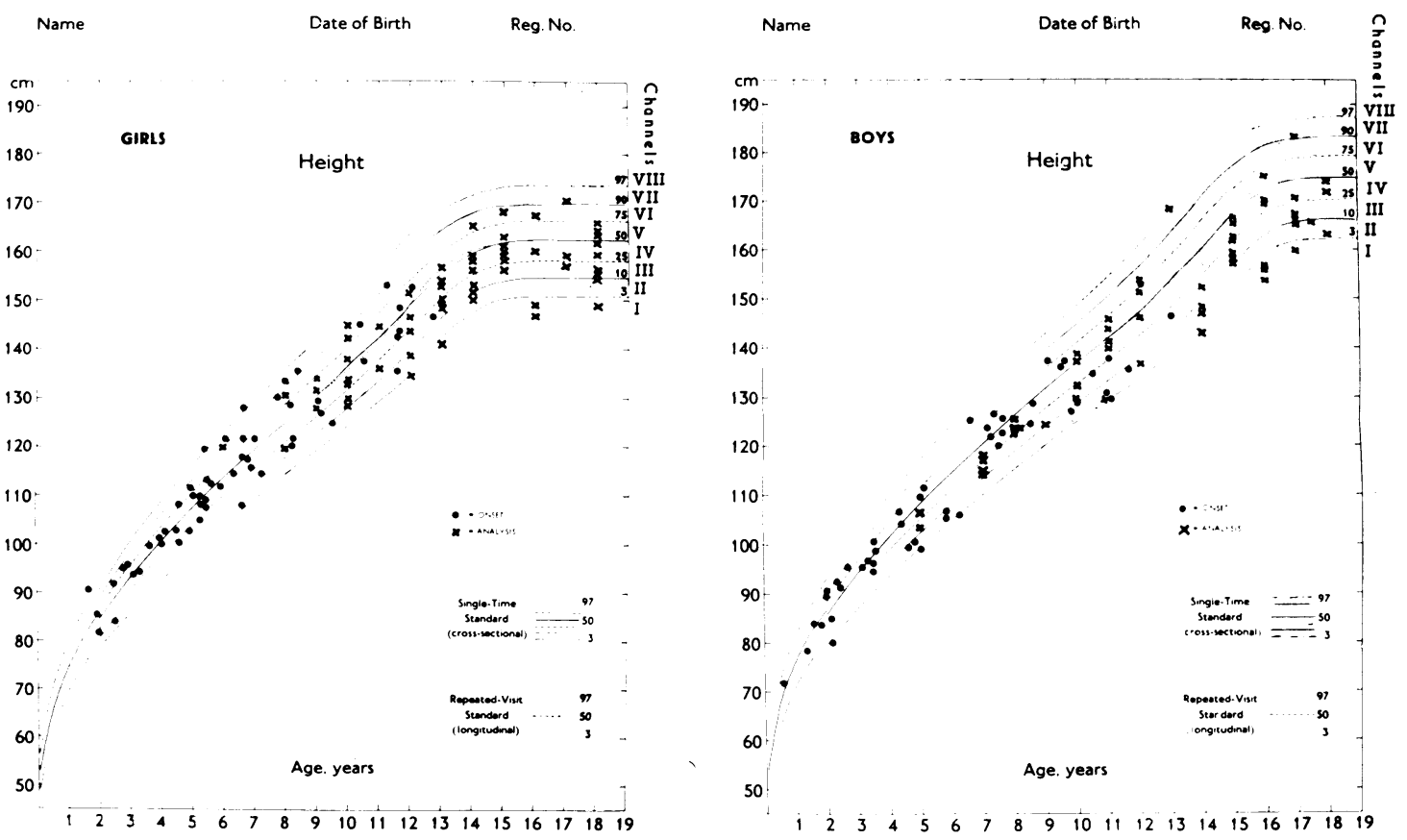

Fig. 2.-(a) Height at onset (O) and analysis $(\times)$ (girls)

(b) Height at onset (O) and analysis $(x)$ (boys).
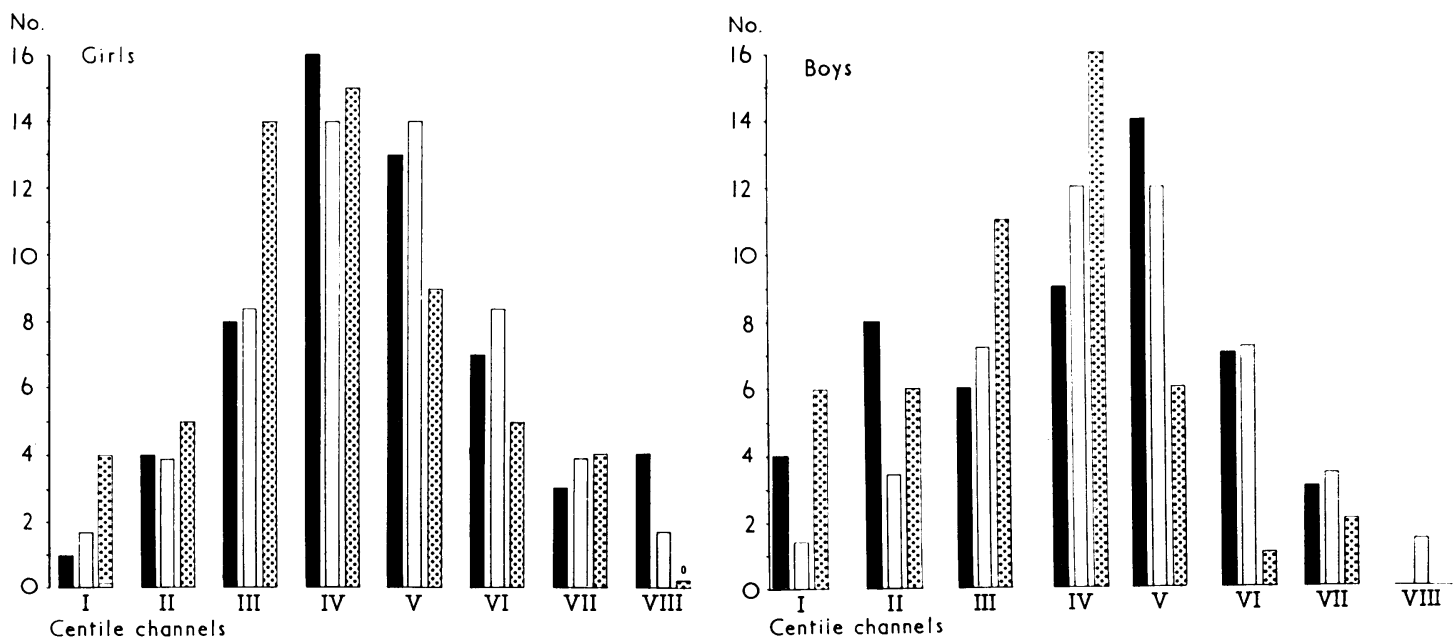

FIG. 3.-(a) Distribution of heights according to centile channels for girls. (b) Distribution of heights according to centile channels for boys.

Key: Actual no. of children in each channel at onset of diabetes.

Expected no. of children in each channel.

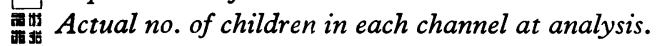


TABLE II

Mean centile value (height) for girls

\begin{tabular}{|c|c|c|c|c|c|c|}
\hline Category & No. & Onset & $\begin{array}{l}\text { Sig. of diff. } \\
\text { from mean }(P)\end{array}$ & Analysis & $\begin{array}{l}\text { Sig. of diff. } \\
\text { from mean }(P)\end{array}$ & $\begin{array}{l}\text { Sig. of diff. } \\
\text { 'within patient } \\
\text { basis' (P) }\end{array}$ \\
\hline $\begin{array}{l}\text { Total girls } \\
\text { Good control } \\
\text { Poor control }\end{array}$ & $\begin{array}{l}56 \\
34 \\
22\end{array}$ & $\begin{array}{l}51 \cdot 7 \\
49 \cdot 5 \\
55 \cdot 1\end{array}$ & $\begin{array}{l}\text { NS } \\
\text { NS } \\
\text { NS }\end{array}$ & $\begin{array}{l}38 \cdot 7 \\
39 \cdot 94 \\
38 \cdot 4\end{array}$ & $\begin{array}{l}0.005-0.001 \\
0.05-0.025 \\
0.05-0.025\end{array}$ & $\begin{array}{l}<0.001 \\
0.005-0.001 \\
0.025-0.02\end{array}$ \\
\hline
\end{tabular}

NS, not significant.

TABLE III

Mean centile value (height) girls

\begin{tabular}{|c|c|c|c|c|c|c|}
\hline Category & No. & Onset & $\begin{array}{l}\text { Sign. of diff. } \\
\text { from mean (P) }\end{array}$ & Analysis & $\begin{array}{l}\text { Sig. of diff. } \\
\text { from mean }(P)\end{array}$ & $\begin{array}{l}\text { Sig. of diff. } \\
\text { 'within patient } \\
\text { basis' }(\mathrm{P})\end{array}$ \\
\hline $\begin{array}{l}\text { Group } 1 \\
\text { Onset: before } \\
6 \text { years } \\
\text { Analysis: at } 9 \\
\text { years }\end{array}$ & 25 & $53 \cdot 94$ & NS & $45 \cdot 94$ & $0 \cdot 4-0 \cdot 3$ & $<0.05$ \\
\hline $\begin{array}{l}\text { Group } 2 \\
\text { Onset: after } 9 \\
\text { years } \\
\text { Analysis after } \\
\text { puberty }\end{array}$ & 10 & $41 \cdot 5$ & NS & $41 \cdot 9$ & $0.3-0.4$ & 0.9 \\
\hline $\begin{array}{l}\text { Group } 3 \\
\text { Onset: before } 6 \\
\text { years } \\
\text { Analysis: after } \\
\text { puberty }\end{array}$ & 11 & 55 & NS & $33 \cdot 68$ & $0.05-0.02$ & $0.05-0.025$ \\
\hline
\end{tabular}

height in groups 1 and 2 (Table III). In group 3, however, there is a significant retardation in height when girls start their diabetes prepubertally $(0.05>\mathrm{P}>0.025)$.

Analysis for boys. Tables IV and V show the mean centile values at onset and analysis for boys. The boys tend to be shorter than the 50th centile but the difference is not statistically significant $(0.7>P>0.6)$ except for boys who have their onset at or around puberty $(0.02>P>0.01)$. The group when analysed at varying periods of follow-up (range 3 to 13 years with a mean of 6.64 years) was shorter than the 50th centile $(0.01>P$ $>0.005)$ and the height centile had fallen on a 'within patient' basis $(P=0.001)$. The wellcontrolled boys were shorter than the 50th centile at analysis $(P=0.001)$ and their height centile had fallen significantly on a 'within patient' basis $(0.01>P>0.005)$. In the poorly controlled group, however, though shorter than the 50th centile at analysis $(0.025>P>0.02)$, the fall in height centile on a 'within patient' basis just escapes statistical significance $(0 \cdot 1>P>0 \cdot 05)$. Adequacy of control

TABLE IV

Mean centile value (height) for boys

\begin{tabular}{|c|c|c|c|c|c|c|}
\hline Category & No. & Onset & $\begin{array}{l}\text { Sig. of diff. } \\
\text { from mean }(P)\end{array}$ & Analysis & $\begin{array}{l}\text { Sig. of diff. } \\
\text { from mean (P) }\end{array}$ & $\begin{array}{l}\text { Sig. of diff. } \\
\text { 'within patient } \\
\text { basis' (P) }\end{array}$ \\
\hline
\end{tabular}

NS, not significant. 
TABLE V

Mean centile value (height) boys

\begin{tabular}{|c|c|c|c|c|c|c|}
\hline Category & No. & Onset & $\begin{array}{l}\text { Sig. of diff. } \\
\text { from mean (P) }\end{array}$ & Analysis & $\begin{array}{l}\text { Sig. of diff. } \\
\text { from mean }(P)\end{array}$ & $\begin{array}{l}\text { Sig. of diff. } \\
\text { 'within patient } \\
\text { basis' (P) }\end{array}$ \\
\hline $\begin{array}{l}\text { Group } 2 \\
\text { Onset: after } 10 \\
\text { Analysis: after } \\
\text { puberty }\end{array}$ & 7 & $25 \cdot 42$ & $0.02-0.01$ & $21 \cdot 2$ & 0.025 & $0.4-0.3$ \\
\hline $\begin{array}{l}\text { Group } 3 \\
\text { Onset: before } \\
6 \text { years } \\
\text { Analysis: after } \\
\text { puberty }\end{array}$ & 6 & $42 \cdot 16$ & NS & $21 \cdot 33$ & $0.005-0.001$ & $0 \cdot 2-0 \cdot 1$ \\
\hline
\end{tabular}

NS, not significant.

had not therefore affected their growth pattern. On analysing the subgroups (Table V) there is no statistically significant retardation in height in groups 1 and 2 . In group 3 though there is no significant drop in height centile, on a 'within patient' basis it is significantly shorter than the 50th centile at analysis.

Separate analysis of the height at onset of diabetic children diagnosed in the last 5 years is shown in Table VI. This shows no significant difference from the normal population or from the patients studied.

\section{TABLE VI}

Mean centile value (MPV) for height (Children diagnosed in past 5 years, 1966-1971)

\begin{tabular}{l|l|l} 
& Boys & Girls \\
\hline No. & $32 \cdot 0$ & $40 \cdot 0$ \\
MPV & $43 \cdot 8$ & $53 \cdot 75$ \\
SD & $28 \cdot 9$ & $28 \cdot 6$ \\
P & NS & NS \\
\hline
\end{tabular}

NS, not significant.

Girls' growth velocity. The mean velocity of the group is normal until puberty but their pubertal growth spurt is reduced and delayed. There is no significant difference between the well and poorly controlled diabetics. When the onset of diabetes occurs before puberty their growth velocity is normal until puberty but the pubertal growth spurt is again reduced and delayed. Girls whose onset of diabetes occurs at or around puberty have a normal growth velocity.
Boys' growth velocity. The mean velocity of the group is normal until puberty but their pubertal growth spurt is reduced and delayed. The well controlled and poorly controlled follow the same pattern until puberty but then a difference emerges. The pubertal growth spurt in the well controlled is lower and later than the group as a whole. The poorly controlled diabetics have a near normal pubertal growth spurt. When the onset of diabetes occurs before puberty, they have a growth velocity slightly below the 50th centile until puberty and at puberty there is a reduced pubertal growth spurt. Boys with onset of diabetes at or around puberty have a normal but slightly delayed pubertal growth spurt.

From the tables of growth velocities, weighted mean velocities were calculated and the difference between the well controlled and poorly controlled ascertained. There was no statistically significant difference between the two groups for girls or boys.

Weight for height analysis. Since at the onset of diabetes the majority of children are dehydrated and in a catabolic state, it was felt that it would be more meaningful to look at their weight/height ratio one year after the onset of diabetes The weight/height ratio of the girls is shown in Table VII. When analysed one year after the onset of diabetes they were significantly heavier than normal children $(P<0.001)$ and became still heavier at analysis 3 years or more after onset ('within patient' basis $0.005>P>0.01$ ). There is no significant difference in weight for height ratio between the well and poorly controlled groups. The boys' data for weight/height is 
TABLE VII

Mean centile value weight/height girls

\begin{tabular}{|c|c|c|c|c|c|c|}
\hline Category & No. & Onset & $\begin{array}{l}\text { Sig. of diff. } \\
\text { from mean (P) }\end{array}$ & Analysis & $\begin{array}{c}\text { Sig. of diff. } \\
\text { from mean }(P)\end{array}$ & $\begin{array}{l}\text { Sig. of diff. } \\
\text { 'within patient } \\
\text { basis' }(P)\end{array}$ \\
\hline $\begin{array}{l}\text { Total } \\
\text { Good control } \\
\text { Poor control }\end{array}$ & $\begin{array}{l}53 \\
33 \\
20\end{array}$ & $\begin{array}{l}67 \cdot 4 \\
68 \cdot 75 \\
65 \cdot 23\end{array}$ & $\begin{array}{l}<0.001 \\
<0.001 \\
0.02-0.01\end{array}$ & $\begin{array}{l}80 \cdot 86 \\
79 \cdot 35 \\
83 \cdot 87\end{array}$ & $\begin{array}{l}<0.001 \\
<0.001 \\
<0.001\end{array}$ & $\begin{array}{l}0.005-0.001 \\
0.02-0.01 \\
0.05-0.025\end{array}$ \\
\hline
\end{tabular}

given in Table VIII. They, like the girls, when analysed one year after the onset of diabetes are significantly heavier than normal children ( $P$ $<0.001)$, and remain so at analysis $(P<0.001)$, but in contrast to girls they do not significantly gain weight when analysed on a 'within patient' basis. The well controlled diabetic boys are heavier at 1 year after onset of diabetes $(P=0.001)$ and remain so at analysis, but again do not significantly alter their height/weight at analysis. Poorly controlled boys, though heavier at 1 year after onset of diabetes, do not remain so at analysis $(0.5>P>0.01)$.

\section{Discussion}

Height at onset. Joslin et al. (1925) first reported that diabetic children were taller than average at diagnosis and this has subsequently been reported by Boyd and Nelson (1928), Wagner et al. (1942), White (1960), Pond (1970), and Craig (1970). This is an attractive finding since insulin is an important anabolic hormone and the hyperinsulinism which precedes overt carbohydrate intolerance might be expected to result in advanced growth, as occurs in the fetuses of mothers with gestational diabetes. Other authors, however, have found no difference in the height of diabetic children at the time of diagnosis (Boyd, 1937; Jackson and Kelly, 1946; Danowski, 1957; Hamne, 1962). Our findings are in agreement with the latter workers. The children in our series are no taller than the standards for British children of Tanner et al. (1966); this still applies when we look at the height at onset of a group of children presenting within the past 5 years. This discrepancy is hard to explain but may be due to regional variations in the height of British children. Craig's children were no taller than the standards of Tanner et al. (1966) for British children but were taller than local standards for Scottish children. No standards are available for the height of children in the Birmingham area, but as far as we are aware our local population does not differ from the national average.

Growth of the diabetic child. White (1960) comments that between 1922 and 1936 failure of linear growth characterized juvenile diabetes. Since the discovery of insulin and the use of intermediate and long-acting preparations, severe growth failure associated with infantilism and hepatomegaly (Mauriac syndrome) has been eliminated. Most diabetic children may now anticipate reaching an adult height within the normal range, but overall a slight but statistically significant degree of retardation of linear growth is present in our series in both sexes. Boyd and Kantrow (1938) suggested that the determining factor was an insufficient food intake but gave no precise details. The calorie intake of our children was reviewed annually. In so far as weight for height ratio gives an index of nutritional state, our children were not malnourished and we feel that calorie intake has not played any part in their growth retardation.

Control of diabetes and growth. Control of diabetes is difficult to define and good control

TABLE VIII

Mean centile value weight/height boys

\begin{tabular}{|c|c|c|c|c|c|c|}
\hline Category & No. & Onset & $\begin{array}{l}\text { Sig. of diff. } \\
\text { from mean (P) }\end{array}$ & Analysis & $\begin{array}{l}\text { Sig. of diff. } \\
\text { from mean }(P)\end{array}$ & $\begin{array}{l}\text { Sig . of diff. } \\
\text { 'within pstient } \\
\text { basis' }(P)\end{array}$ \\
\hline $\begin{array}{l}\text { Total } \\
\text { Good control } \\
\text { Poor control }\end{array}$ & $\begin{array}{l}44 \\
25 \\
19\end{array}$ & $\begin{array}{l}69 \cdot 1 \\
74 \cdot 86 \\
61 \cdot 68\end{array}$ & $\begin{array}{l}<0.001 \\
<0.001 \\
0.05-0.025\end{array}$ & $\begin{array}{l}67 \cdot 0 \\
71 \cdot 24 \\
61 \cdot 5\end{array}$ & $\begin{aligned} & <0.001 \\
& <0.001 \\
0.1 & -0.5\end{aligned}$ & $\begin{array}{l}0 \cdot 8-0 \cdot 7 \\
0 \cdot 8-0 \cdot 7 \\
0 \cdot 8-0 \cdot 7\end{array}$ \\
\hline
\end{tabular}


even more so. The criteria used by various authors to define control vary widely and it may not therefore be meaningful to compare our results too closely with other series. On the basis of our criteria, however, control has no effect on growth. Danowski (1957), Sterky (1963, 1967), and Craig (1970) reached the same conclusion. Our series in fact shows a tendency, at least in boys, for growth to be better in the poorly controlled group. Wagner et al. (1942) analysing growth in relation to control found a slight predominance of very good control in favour of growth retarded children. It is not our intention to dispute the overall benefit of good control in the management of the diabetic child, but linear growth is not a satisfactory criterion by which control may be assessed.

Growth during puberty. When growth is analysed in relation to duration of diabetes before puberty it is apparent that the growth retardation of the group as a whole is chiefly due to a delayed and reduced pubertal growth spurt in those children who developed diabetes 3 years or more before puberty. The onset of diabetes shortly before or during puberty does not affect the peak velocity achieved. Wagner et al. (1942) found that the diabetic child was most susceptible to growth retardation between the twelfth and sixteenth years of life and from the second to sixteenth year of diabetes. Bergqvist (1954) followed 8 boys and 10 girls whose onset was between 10 and 15 years. Among boys he found a slight tendency to retardation of growth, though statistically not significant, and among girls there was no such tendency; whereas he found retarded growth in those with onset before 5 years and also in those with onset between 5 and 10 years. Knowles et al. (1965) found mean heights of adult diabetic men and women to be shorter than average and that the decrease in stature was mainly in those with diabetes diagnosed before the growth spurt.

In conclusion we feel that the growth of diabetic children is not severely retarded but when it occurs it is related to the duration of the disease before puberty and is principally due to a delayed and reduced pubertal growth spurt and is not related to adequacy of control.
Further studies to correlate the timing of pubertal changes and the skeletal maturation with the pubertal growth spurt of diabetic children are in progress in our department.

We thank Dr. John Waterhouse for help with the statistical analysis, and the past and present consultant paediatricians of the Children's Hospital, Birmingham, who referred cases to our clinic.

\section{REFERENCES}

Bergqvist, N. (1954). The growth of juvenile diabetics. Acta Endocrinologica, 15, 133.

Boyd, J. D. (1937). Diseases of the pancreas-diabetes. In Practice of Paediatrics, Vol. 3, Chapter 12. Ed. by J. Brennemann. Prior, Hagerstown. U.S.A.

Boyd, J. D., and Kantrow, A. H. (1938). Retardation of growth in diabetic children. American Fournal of Diseases of Children, $55,460$.

Boyd, J. D., and Nelson, M. V. (1928). Growth studies of children with diabetes mellitus. American fournal of Diseases of Children, 35, 753.

Craig, J. O. (1970). Growth as a measurement of control in the management of diabetic children. Postgraduate Medical fournal, 46, September Supplement, 607.

Danowski, T. S. (1957). Somatic Growth and Development of the Juvenile Diabetic: Endocrine Profiles. In Diabetes Mellitus with Emphasis on Children and Young Adults, Chapter 21, p. 387. Williams and Wilkins, Baltimore.

Hamne, B. (1962). Growth in a series of diabetic children on identical treatment with 'free' diet and insulin, 1944-1960. Acta Paediatrica Scandinavica, Suppl. 135, 72.

Jackson, R. L., and Kelly, H. G. (1946). Growth of children with diabetes mellitus in relationship to level of control of the disease. Fournal of Pediatrics, 29, 316.

Joslin, E. P., Root, H. F., and White, P. (1925). The growth, development and prognosis of diabetic children. Fournal of the American Medical Association, 85, 420.

Knowles, H. C., Guest, G. M., Lampe, J., Kessler, M., and Skillman, T. G. (1965). The course of juvenile diabetes treated with unmeasured diet. Diabetes, 14, 239.

Pond, H. (1970). Some aspects of growth in diabetic children. Postgraduate Medical fournal, 46, September Supplement, 616.

Sterky, G. (1963). Diabetic schoolchildren. Acta Paediatrica Scandinavica, Suppl. 144, 1.

Sterky, G. (1967). Growth pattern in juvenile diabetes. Acta Paediatrica Scandinavica, Suppl. 177, 80.

Tanner, J. M., Whitehouse, R. H., and Takaishi, M. (1966). Standards from birth to maturity for height, weight, height velocity, and weight velocity: British children 1965. Archives of Disease in Childhood, 41, 454 and 613.

Wagner, R., White, P., and Bogan, I. K. (1942). Diabetic dwarfism. American Fournal of Diseases of Children, 63, 667.

White, P. (1960). Childhood diabetes. Its course and influence on the second and third generations. Diabetes, $9,345$.

Correspondence to Dr. P. H. W. Rayner, The Children's Hospital, Ladywood Middleway, Birmingham B16 8ET. 